Eur. J. Clin. Chem. Clin. Biochem.

Vol. 32, 1994, pp. 853-858

(C) 1994 Walter de Gruyter \& Co. Berlin · New York

\title{
A Rapid Assay for the Quantification of Myoglobin: Evaluation and Diagnostic Relevance in the Diagnosis of Acute Myocardial Infarction
}

\author{
By H. Baum ${ }^{1}$, P. Booksteegers ${ }^{2}$, G. Steinbeck ${ }^{2}$ and D. Neumeier ${ }^{1}$ \\ 1 Institut für Klinische Chemie \\ 2 Medizinische Klinik I \\ Klinikum Großhadern der Universität München
}

(Received April 27/July 27, 1994)

Summary: We evaluated a new, fast, quantitative, turbidimetric assay (TurbiTimeSystem, Behringwerke AG, Marburg, Germany) for the determination of myoglobin concentration in serum. Within-run imprecision $(n=10)$ was $<3.7 \%$ in controls ranging from 81.1 to $621.4 \mu \mathrm{g} / \mathrm{l}$ and between-day imprecision $(\mathrm{n}=50)$ was $<6 \%$ in controls ranging from 69.5 to $623.4 \mu \mathrm{g} / \mathrm{l}$. The assay is linear over the measuring range and interfering substances such as bilinibin, haemoglobin or haptoglobin do not interfere but triacylglycerol-rich samples are only measureable after brief ultracentrifugation. EDTA- or citrate-treated samples display depressed myoglobin concentration when compared with serum samples. The upper reference limit for apparently healthy individuals $(\mathrm{n}=100,50$ female and $50 \mathrm{male})$ is $61.5 \mu \mathrm{g} / \mathrm{l}$. Comparison with nephelometry revealed a good correlation $(\mathrm{r}=0.982)$ between the two methods with the regression equation: turbidimetric assay $=5.53+1.02 \mathrm{x}$ nephelometric assay.

Serial determination of myoglobin concentration and creatine kinase in 18 patients with proven acute myocardial infarction showed in general an equal diagnostic significance for both analytes. In the first 4 hours after onset of chest pain, the determination of myoglobin can have an advantage, since it is released into the blood stream at an earlier stage, but thereafter myoglobin can lead to false negative diagnosis. Therefore, determination of creatine kinase and its isoenzyme MB is still the diagnostic strategy of choice in the diagnosis of acute myocardial infarction.

\section{Introduction}

Myoglobin is a low-molecular mass, oxygen-binding haemoprotein $\left(M_{\mathrm{r}} 17700\right)$ of the skeletal and cardiac muscle (1). Elevation of the myoglobin concentration above the upper reference limit is normally caused by the injury of cardiac muscle, e.g. acute myocardial infarction, provided skeletal muscle has been excluded as a source. In addition, physical exercise (2) or decreased renal function with subsequent decreased myoglobin clearance can result in elevated myoglobin levels in blood (3). After acute myocardial infarction, myoglobin is rapidly released from necrotic myocardium in advance of cytoplasmic enzymes such as creatine kinase $\left(\mathrm{EC}\right.$ 2.7.3.2.) $\left.{ }^{1}\right)$ or its isoenzyme creatine kinase-MB $\left.{ }^{1}\right)(4$, 5). Therefore, myoglobin can be used for the early diag- nosis of acute myocardial infarction (6). In the routine clinical chemistry laboratory, myoglobin concentrations can be determined by radioimmunoassay $(7,8)$ or immunonephelometry (9). These methods are sensitive but time consuming and not suitable for emergency testing. A latex agglutination assay $(5,10)$ gives only semiquantitative results and is less sensitive. The aim of our study was to evaluate a new fast and quantitative turbidimetric assay for the determination of myoglobin and to test the diagnostic relevance in the early phase of acute myocardial infarction.

\footnotetext{
1) Enzymes:

Creatine kinase EC 2.7.3.2

Creatine kinase-MB
} 


\section{Materials and Methods}

\section{Refcrence individuals and patients}

Sera were obtained from

- 100 patients with elevated creatine kinase levels; reference limits in this laboratory are $80 \mathrm{U} / 1$ for male and $70 \mathrm{U} / 1$ for female (11),

- 100 apparently healthy persons (50 males and 50 females) to determine the reference interval.

- 18 patients with acute myocardial infarction (at admission and at definite times after onset of chest pain); acute myocardial infarction was confirmed with typical changes in ECG and courses of creatine kinase and creatine kinase-MB.

Furthermore, two plasma samples with K-ethylenediaminetetraacetate (EDTA) and Na-citrate as an anticoagulant were collected from 20 individuals.

All specimens were analysed within 24 hours after venipuncture. The specimens from the 18 patients with acute myocardial infarction were stored at $-20^{\circ} \mathrm{C}$ until analysis.

\section{Immunoturbidimetric method}

The determination of serum and plasma myoglobin was performed using the TurbiTimeSystem (Behringwerke AG, Marburg, Germany), a turbidimetric immunoassay for the single testing of plasma proteins. The calibration information needed for the assay is charge-dependent and inserted as a bar code in the package information. For measurement of myoglobin, a cuvette is filled with $50 \mu \mathrm{l}$ of undiluted serum or plasma, inserted into the system, and $500 \mu \mathrm{l}$ reagent solution (Turbiquant Myoglobin, code No. QWNK, Behringwerke AG) is added. The test result is presented within 2 minutes. The pre-programmed measuring range lies between 50 and $650 \mu \mathrm{g} / \mathrm{l}$.

\section{Immunonephelometric method}

The BNA System (Behringwerke AG) is a fully automated system for immunonephelometric examination of plasma proteins. Myoglobin measurement is carried out with latex particles coated with anti-myoglobin antibodies (NA-Latex Myoglobin Test, Behringwerke $A G)$ (9). The measuring range extends from 21.9 to 350 $\mu \mathrm{g} / \mathrm{l}$ with a coefficient of variation of $10 \%$ at $100 \mu \mathrm{g} / \mathrm{l}$.

\section{Creatine kinase and creatine kinase-MB}

Creatine kinase and creatine kinase-MB were determined using dry-film technology on a fully automated analyser (Ektachem $700 X R$, Eastman Kodak, Rochester, NY). The coefficients of variation were $4.1 \%$ for creatine kinase at $100 \mathrm{U} / \mathrm{l}$ and $4.9 \%$ for creatine kinase-MB at $36 \mathrm{U} / \mathrm{l}$.

\section{Evaluation}

Evaluation was performed according the recommendations of Singer et al. (12). All measurements were performed in duplicate.

\section{Statistical analysis}

Correlations were calculated by linear regression analysis.

\section{Results}

Imprecision

Three different pooled human sera with elevated myo- ${ }^{\circ}$ globin concentrations and a commercial control serum
Tab. 1 Within-run and between-day imprecision of the turbidimetric determination of myoglobin concentration.

\begin{tabular}{lcccc}
\hline & $\begin{array}{c}\text { Control } \\
\text { sample }\end{array}$ & $\begin{array}{c}\text { Serum } \\
\text { pool I }\end{array}$ & $\begin{array}{c}\text { Serum } \\
\text { pool II }\end{array}$ & $\begin{array}{c}\text { Serum } \\
\text { pool III }\end{array}$ \\
\hline Intra-assay imprecision: & & & & \\
Myoglobin, $\mathrm{x}(\mu \mathrm{g} / \mathrm{l})$ & 101.8 & 81.1 & 160.3 & 621.4 \\
Myoglobin, s $(\mu \mathrm{g} / \mathrm{l})$ & 3.74 & 2.4 & 2.83 & 14 \\
$\mathrm{CV}(\%)$ & 3.69 & 2.96 & 1.76 & 2.25 \\
$\mathrm{n}$ & 10 & 10 & 10 & 10 \\
& & & & \\
Inter-assay imprecision: & & & & \\
Myoglobin, $\overline{\mathrm{x}}(\mu \mathrm{g} / \mathrm{l})$ & 98.6 & 69.5 & 154.5 & 623.4 \\
Myoglobin, s $(\mu \mathrm{g} / \mathrm{l})$ & 2.99 & 4.16 & 5.95 & 17.3 \\
CV (\%) & 3.03 & 5.99 & 3.85 & 2.77 \\
$\mathrm{n}$ & 52 & 51 & 52 & 52 \\
\hline
\end{tabular}

(Behringwerke AG, Marburg, Germany) were analysed 10 times to estimate intra-assay imprecision (tab. 1). For inter-asșay reproducibility all controls were tested over 50 consecutive days (tab. 1).

\section{Linearity}

The linearity of dilution was investigated using serum samples containing high myoglobin concentrations. Serial dilutions $(10+0,9+1, \ldots, 0+10)$ were made with $\mathrm{NaCl}$ or enzyme diluent. Figure 1 shows the results of serial dilution of one of these serum samples. After correction of the measured value for the dilution factor, recovery was found to be between 81 and $101 \%$ using $\mathrm{NaCl}$, and 88 and $101 \%$ using enzyme diluent to dilute the myoglobin concentration of undiluted samples (tab. 2).

\section{Interfering substances}

Sera containing potential interfering substances were added to myoglobin-rich serum samples in different ra-



Fig. 1 Linearity of dilution. X-axis shows the fraction of serum, $(\square)$ dilution with enzyme diluent, $(\dot{-}---\infty)$ with $\mathrm{NaCl}$ as a diluent for one exemplary serum. 
Tab. 2 Dilution of myoglobin-containing serum samples with enzyme diluent and $\mathrm{NaCl}$. Shown is the percentual deviation from the theoretical value for every dilution step.

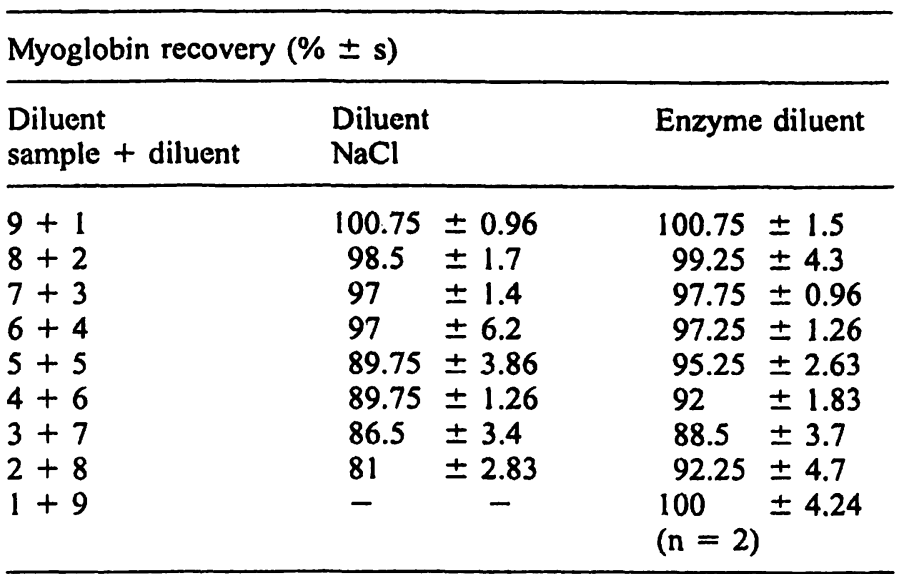

tios $(10+0,9+1, \ldots, 0+10)$. No interferences were shown with bilirubin, haemoglobin and haptoglobin at final concentrations of 2,30 and $7000 \mathrm{mg} / \mathrm{l}$ respectively. The concentration of myoglobin in serum that was enriched with triacylglycerol could not be determined. However, after brief ultracentrifugation $(5 \mathrm{~min}$, $240000 \mathrm{~g}$ ) no interferences were found (fig. 2).

\section{Effect of probe}

Figure 3 shows the comparison of serum vs. EDTA- and citrate-plasma. In both plasmas, the amount of myoglobin measured is less than that found in serum; the EDTA plasma showed only $92 \%$ of the actual myoglobin concentration, and the citrate plasma $89 \%$.



Fig. 2 Effect of potential interfering substances. $X$-axis shows the fraction of serum, $(+-+)$ dilution with bilirubin-containing serum, $(\square-\square)$ dilution with haemolytic serum, ( $\square$ - dilution with haptoglobin-rich serum, (-) dilution with triacylglycerol-rich serum after brief ultracentrifugation.

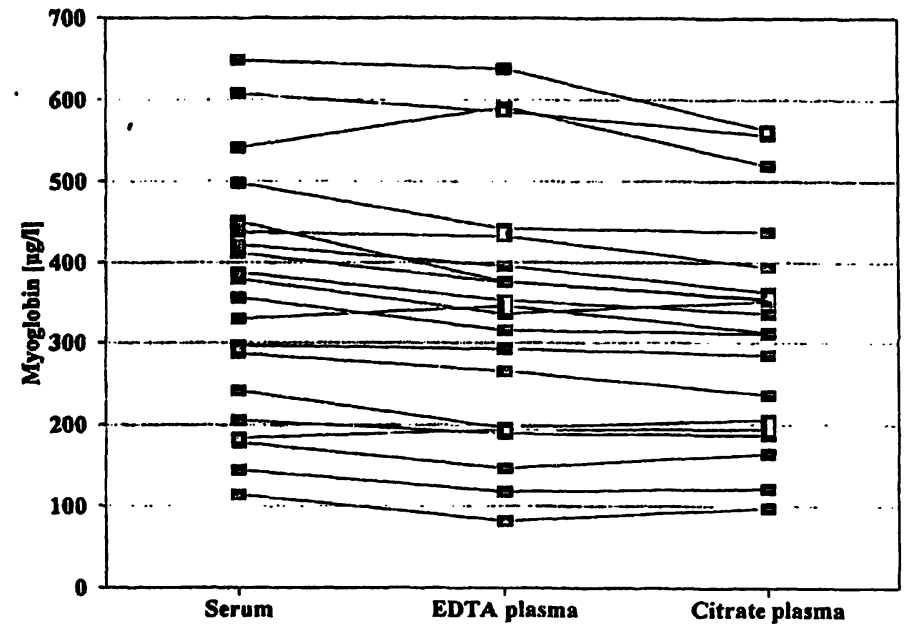

Fig. 3 Comparison of myoglobin results in serum, EDTA- and citrate-plasma in 20 patients. The corresponding samples are connected by lines. Apparent myoglobin concentration is depressed in plasma in contrast to serum samples.

Tab. 3 Stability of myoglobin in serum in dependence on temperature and time.

\begin{tabular}{llllll}
\hline \multicolumn{6}{l}{ Myoglobin $(\mu \mathrm{g} / \mathrm{l})$} \\
\hline Sample & $\begin{array}{l}\text { Actual } \\
\text { value }\end{array}$ & $\begin{array}{c}+20^{\circ} \mathrm{C} \\
(2 \text { days })\end{array}$ & $\begin{array}{l}+4{ }^{\circ} \mathrm{C} \\
(1 \text { week })\end{array}$ & $\begin{array}{l}-20^{\circ} \mathrm{C} \\
(2 \text { weeks })\end{array}$ & $\begin{array}{l}-20^{\circ} \mathrm{C} \\
(3 \text { months })\end{array}$ \\
\hline 1 & 490 & 478.5 & 461 & 490.5 & 458 \\
2 & 103.5 & 99.25 & 104.5 & 107.5 & 110.5 \\
3 & 358.5 & 348.5 & 372.5 & 354.5 & 334.5 \\
4 & 362.5 & 342.5 & 354 & 357 & 352 \\
5 & 69.3 & 60.75 & 69.25 & 74 & 68.4 \\
6 & 179.5 & 159 & 169.5 & 166 & 162.5 \\
7 & 226 & 203 & 210.5 & 224.5 & 236.5 \\
8 & 263 & 295.5 & 288 & 289 & 288.5 \\
9 & 320 & 312 & 311 & 311 & 302 \\
10 & 492 & 488.5 & 505 & 491 & 485.5 \\
\hline
\end{tabular}

\section{Stability}

Ten serum samples were divided into aliquots and stored either at room temperature for 2 days, at $+4{ }^{\circ} \mathrm{C}$ for one week or at $-20^{\circ} \mathrm{C}$ at least 3 months. In contrast to fresh samples, no alteration in myoglobin concentration was found (tab. 3).

\section{Reference values}

Figure 4 shows the cumulative distribution of the myoglobin concentration in the serum samples of the reference population. The upper reference limit $(97.5 \%$ percentile) was found to be $61.5 \mu \mathrm{g} / \mathrm{l}$, and the maximum value was $159 \mu \mathrm{g} / \mathrm{l}$.

\section{Method comparison}

Ninety-one serum samples with myoglobin concentrations between 50 and $650 \mu \mathrm{g} / \mathrm{l}$ in the immunoturbidimet- 




Fig. 4 Distribution of myoglobin concentration in apparently healthy individuals ( 50 females and 50 males). Bars show the percentual, filled squares the cumulative portion of the total number.



Fig. 6 Time courses of creatine kianse activity in 18 patients with acute myocardial infarction.

ric assay were re-evaluated using immunonephelometry. The following correlation was obtained: $y=1.02 x$ $+5.53, \mathrm{r}=0.982$ (fig. 5).

\section{Diagnostic implications}

To investigate the diagnostic implication of myoglobin determination in the early phase of acute myocardial infarction, serum samples were collected from 18 patients with proven acute myocardial infarction at admission and at $2,4,6,9,12,15,18$ and then every 6 hours for at least 60 hours after onset of chest pain. Myoglobin concentration and creatine kinase activity were measured in all samples. Figure 6 and 7 summarize the time courses of creatine kinase activity and myoglobin concentration of all 18 patients. Myoglobin appeared at con? centrations above the upper reference limit on average

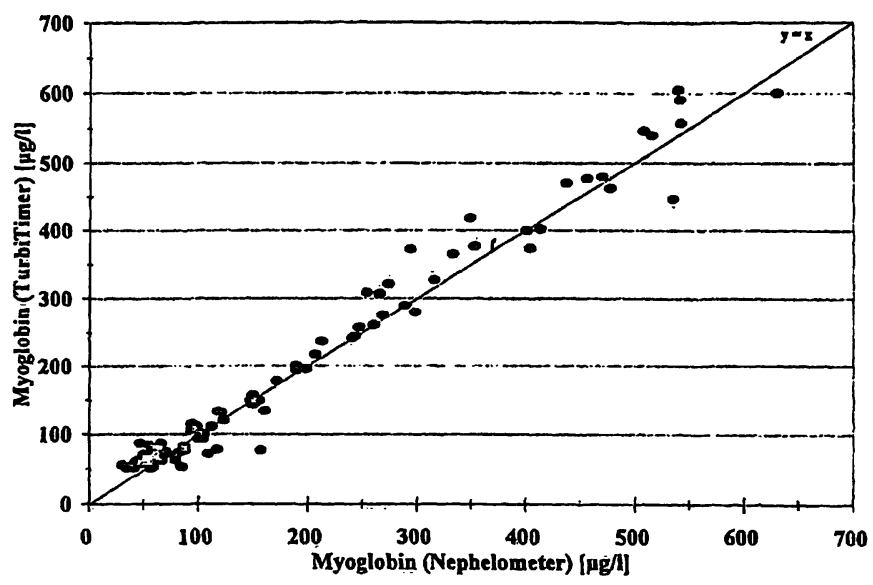

Fig. 5 Comparison of myoglobin concentration in serum determined by immunonephelometry and immunoturbidimetry. A good correlation was found: $(y=1.02 x+5.53, r=0.982)$.

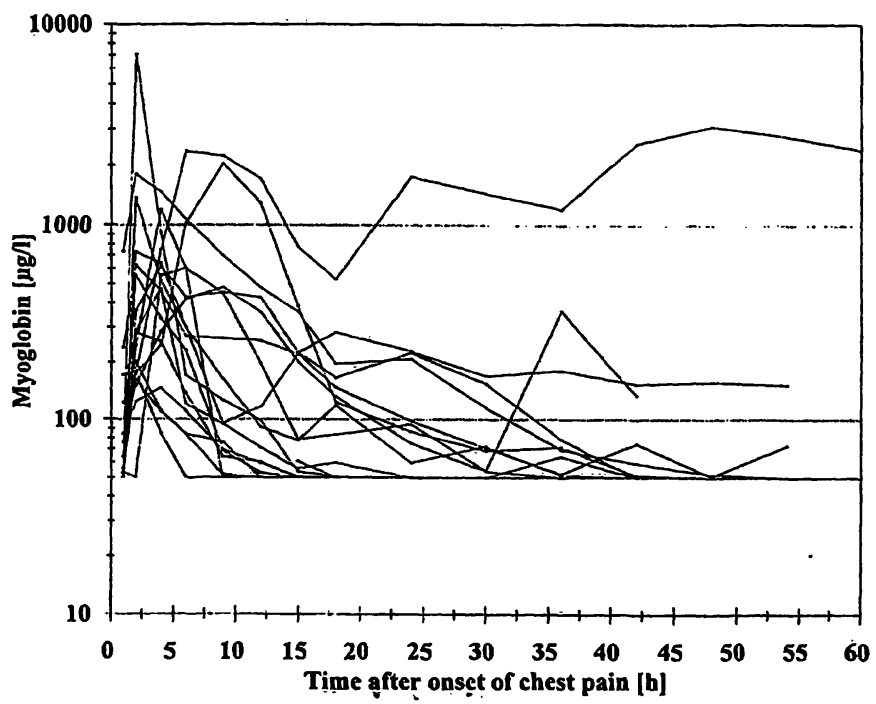

Fig. 7 Time courses of myoglobin concentration in 18 patients with acute myocardial infarction. Myoglobin concentrations below the detection limit of the assay are set at $50 \mu \mathrm{g} / \mathrm{l}$.

$2.9 \pm 1.7$ hours after onset of chest pain. In contrast, creatine kinase activity above the upper reference limit was first observed on average $5.3 \pm 2$ hours after acute myocardial infarction. The peak value for myoglobin was reached $4.8 \pm 3.2$ hours after acute myocardial infarction, for creatine kinase activity at $15.2 \pm 7.4$ hours. At $23.9 \pm 13.8$ hours after onset of chest pain, myoglobin concentration returned to within the reference interval, whereby 7 patients showed a so called "staccato phenomenon" (13). Creatine kinase activity returned to the normal range on average $51.7 \pm 15.6$ hours after acute myocardial infarction, during which time six patients showed a second peak.

Elevated myoglobin or creatine kinase activity levels alone are insufficient for the diagnosis of acute myocardial infarction. Therefore, it is necessary to determine 
the level in a second, independent sample approximately one hour later to confirm that it displays a significant increase compared with the starting value. Figure 8 and 9 show creatine kinase activity and myoglobin concentration in the first two blood collections for each patient. In the first sample, the myoglobin concentration lie above the upper reference limit for all patients. In one patient the second value is, however decreased compared with the first. In 10 patients, both values of creatine kinase activity are within the reference limit, but in all 18 patients the second value is higher than the first.

\section{Discussion}

\section{Evaluation}

As described under results, the TurbiTimeSystem is a fast, reliable and simple method for the quantitative determination of myoglobin concentrations in serum. In-

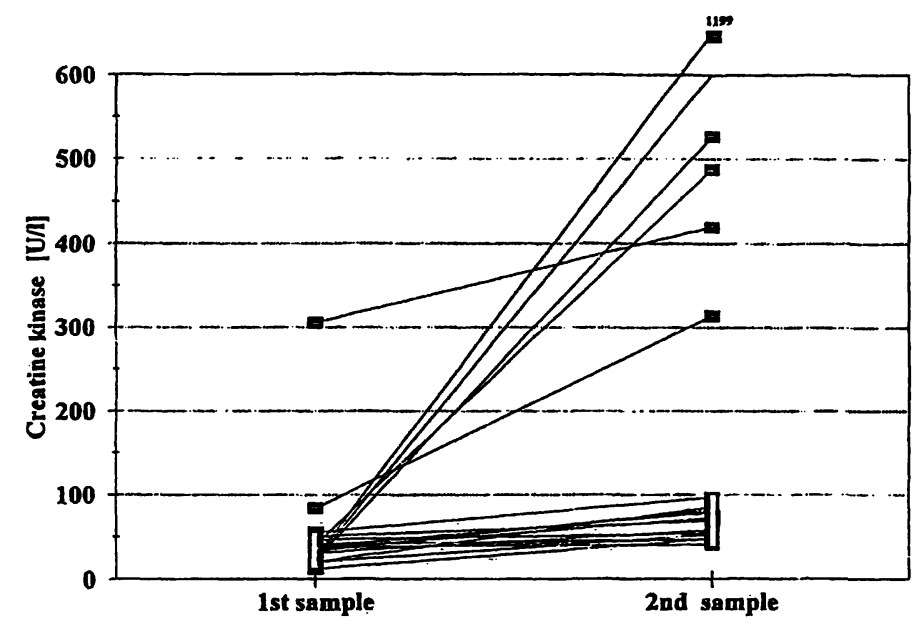

Fig. 8 Comparison of the creatine kinase concentrations of the first two blood samples in all 18 patients after acute myocardial infarction.



Fig. 9 Comparison of the myoglobin concentrations of the first two blood samples in all 18 patients after acute myocardial infarction. tra-assay and inter-assay imprecision is low and comparability with immunonephelometry is good. With the exception of triacylglycerol, potentially interfering substances do not disturb the assay. Similar results were obtained by Delanghe et al. (14) and Mair et al. (15), but correlation with RIA was inferior. Lipid extraction using an extraction agent leads to an underestimation of myoglobin of up to $36 \%$ (14). This can be avoided using brief ultracentrifugation.

Myoglobin levels in serum are in general higher than in EDTA- or citrate-treated plasma samples, but the lower results for citrate plasma are primarily dependent on the dilution factor. Therefore, reference ranges for each type of material are necessary. For serum myoglobin, we found an upper reference limit of $61.5 \mu \mathrm{g} / \mathrm{l}$. This is in general in agreement with the values obtained by Mair et al. (15) who found an upper reference limit of 70 $\mu \mathrm{g} / \mathrm{l}$ and by Delanghe et al. (14) who found sex-related reference limits of $68.6 \mu \mathrm{g} / \mathrm{l}$ for females and $74.1 \mu \mathrm{g} / \mathrm{l}$ for males. In conclusion, the immunoturbidimetric determination of myoglobin is a viable alternative to other quantitative assays. Its advantages are that it is a fast, reliable method and thus suitable for an emergency laboratory or small laboratory units.

\section{Diagnostic significance}

In the early phase of acute myocardial infarction there are no differences in the predictive value of myoglobin concentration or creatine kinase activity $(1,5,8,16)$. As only a semi-quantitative latex-test for determination of myoglobin was hitherto available $(5,10)$, it was not practicable to determine myoglobin concentration in emergency situations. The TurbiTimeSystem permits the rapid, quantitative determination of myoglobin concentration. This raises afresh the question of whether the determination of myoglobin concentration is superior to creatine kinase activity in the early phase diagnosis of acute myocardial infarction.

Both quantities have the same tissue distribution, above all in skeletal and cardiac muscle $(1,17)$. In addition, physical exercise or disease affecting skeletal muscles (2) as well as decreased renal function will lead to an increased myoglobin concentration (3). Taking these factors into consideration and the dynamics of tissuerelease and clearance, both analytes can be recruited in the diagnosis of acute myocardial infarction.

Our findings indicate that myoglobin, in comparison with creatine kinase, shows earlier values above the upper reference limit ( 2.9 vs. 5.3 hours) in concordance with other data $(15 a \& b, 18,19,20)$. The concentration peaks much earlier (4.8 vs. 15.2 hours) and myoglobin returns to the normal range earlier than creatine kinase 
(23.9 vs. 51.7 hours). Because the molecular mass of myoglobin is lower than that of creatine kinase, it appears before creatine kinase in the blood stream and is rapidly cleared through the kidneys. On the other hand, our investigations show that creatine kinase activity rises in all patients with acute myocardial infarction in two consecutive blood samples, even if the second value for creatine kinase in 10 out of 18 patient lies within the normal range (fig. 7). In contrast, the second myoglobin sample of patient even showed a decreased value (fig. 8).

Therefore, both quantities have equal significance in the diagnosis of acute myocardial infarction. In the first hours after the onset of chest pain, myoglobin has a diagnostic advantage as it is released into the blood stream earlier than creatine kinase. If the first blood sample from patients with acute myocardial infarction is taken later than 4 hours after onset of chest pain, myoglobin can lead to false negative diagnosis. For this reason, the simul-

\section{References}

1. Kagen, L. J. (1984) Extension of myocardial infarction and serum myoglobin. Int. J. Cardiol. 6, 337-339.

2. Neumeier, D. (1987) Herz- und Skelettmuskulatur. In: Lehrbuch der Klinischen Chemie und Pathobiochemie, 1st edn. (Greiling, H. \& Gressner, A. M., eds.) Schattauer, Stuttgart, pp. 605-634.

3. Hällgren, Karlsson, F. A., Roxin, L-E. \& Venge, P. (1978) Myoglobin turnover - Influence of renal and extrarenal factors. Scand. J. Lab. Clin. Med. 91, 246-254.

4. Collison, P. O., Rosalki, S. B., Flather, M., Wolman, R. \& Evans, T. (1988) Early diagnosis of myocardial infarction by time sequential enzyme measurements. Ann. Clin. Biochem. $25,376-382$.

5. Bachem, M. G., Paschen, K., Strobel, B., Keller, H. E. \& Kleinschnitger, B. (1983) Myoglobin-Latextest. Dtsch. Med. Wochenschr. 108, 1190-1194.

6. Adams III, J. E., Abendschein, D. R. \& Jaffe, A. S. (1993) Biochemical markers of myocardial injury - Is MB creatine kinase the choice for the 1990s? Circulation 88, 750-763.

7. Roxin, L-E., Venge, P. \& Wide, L. (1980) A fast and sensitive radioimmunoassay of human myoglobin for use in the early diagnosis of heart infarction. Clin. Chim. Acta 107, 129-134.

8. Honda, H. \& Katayama, T. (1984) Detection of myocardial infarction extension or reattack by serum myoglobin radioimmunoassay. Int. J. Cardiol. 6, 325-335.

9. Delanghe, J. R., Chapelle, J-P. \& Vanderschueren (1990) Quantitative nephelometric assay for determining myoglobin evaluated. Clin. Chem. 36, 1675-1678.

10. Koch, D-D. \& Kalmbach, C. (1982) Einsatz eines MyoglobinLatextestes in der Diagnostik des Herzinfarktes. Ärztl. Lab. $28,381-385$.

11. Stein, W. (1992) Creatin-Kinase (CREATINE KINASE), Creatin-Kinase (MB). In: Labor und Diagnose, 4th edn. (Thomas, L., ed.) Medizinische Verlagsgesellschaft, Marburg, p. 92.

12. Singer, R., Clarke, S. F., Crafter, V. A., Gray, B. C., Kilshaw, D., Randell, J. A., Robinson, J. L. \& White, J. M. (1987) Selection and evaluation of laboratory instrumentation in clinical chemistry: 11. Guidelines for selection and evaluation. Med. Lab. Sci. 44, 6-14. taneous determination of creatine kinase and its isoenzyme creatine kinase-MB is still the diagnostic strategy of choice for the diagnosis of acute myocardial infarction (4). On the other hand, in monitoring thrombolysis therapy of acute myocardial infarction, the determination of myoglobin in superior to creatine kinase. As myoglobin is rapidly released after succesśful thrombolysis into the blood, increasing values of myoglobin show effective recanalisation within a few hours (20).

Recently, a new, fast system that makes use of "dry chemistry" procedures has been made available (OPUS, Behringwerke AG, Marburg, Germany). Whether or not this new technology is superior to turbidimetry as a fast technique for emergency use has yet to be demonstrated.

\section{Acknowledgement}

The authors wish to thank Dr. M. Lammers from Behringwerke AG for his support and for providing the reagents and the TurbiTimeSystem, Mrs. R. Mezger and Miss $I$. Schwab for skilful technical assistance and Mr. M. Page for reading the manuscript.

13. Gasser, R. (1986) Myoglobin und akuter Myokardinfarkt. Innere Medizin 13, 118-126.

14. Delanghe, J. R., Chapelle, J-P., El Allaf, M. \& DeBuyzere, M. (1991) Quantitative turbidimetric assay for determining myoglobin evaluated. Ann. Clin. Biochem. 28, 474-479.

15 a. Mair, J., Artner-Dworzak, E., Lechleitner, P., Morass, B., Smidt, J., Wagner, I., Dienstl, F. \& Puschendorf, B. (1992) Early diagnosis of acute myocardial infarction by a newly developed rapid immunoturbidimetric assay for myoglobin. Br. Heart J. 68, 462-468.

15 b. Roxin, R-E., Cllhed, I., Groth, T., Hällgren, T. \& Venge, P. (1984) The value of serum myoglobin determination in the early diagnosis of acute myocardial infarction. Acta Med. Scand. $215,417-425$.

16. Neumeier, D. (1981) Tissue specific distribution of creatine kinase isoenzymes. In: Creatine Kinase Isoenzymes (Lang, H., ed.) Springer Verlag, Berlin, pp. 85-115.

17. Cairns, J. A., Missirlis, E. \& Walker, W. H. C. (1983) Usefulness of serial determination of myoglobin and creatine kinase in serum compared for assessment of acute myocardial infarction. Clin. Chem. 29, 469-473.

18. Grenadier, E., Keidar, S., Kahana, L., Alpan, G., Marmur, A. \& Palant, A. (1983) The roles of serum myoglobin, total CPK, and creatine kinase-MB isoenzyme in the acute phase of myocardial infarction. Am. Heart J. 105, 408-416.

19. Gibler, W. B., Gibler, C. D., Weinshenker, E., Abbottsmith, C., Hedges, J. R., Barsan, W. G., Sperling, M., Chen, I. W., Embry, S. \& Kereiakes, D. (1987) Myoglobin as an early indicator of acute myocardial infarction. Ann. Emerg. Med. 16, $851-856$.

20. Puschendorf, B. (1992) Myoglobin. In: Labor und Diagnose 4th ed. (Thomas, L., ed.) Medizinische Verlagsgesellschaft, Marburg, pp. 830-833.

Dr. Hannsjörg Baum

Institut für Klinische Chemie

und Pathobiochemie

Klinikum rechts der Isar

der TU München

Ismaninger Straße 22

D-81675 München

Germany 